\title{
A EDUCAÇÃO FíSICA NA EDUCAÇÃO INFANTIL (O A 3 ANOS): O ESTADO DA ARTE A PARTIR DE PUBLICAÇÕES DA ANPED
}

José Ricardo Silva

Universidade Estadual Paulista - FCT/UNESP, Presidente Prudente, SP. e-mail: ricardo.unesp@hotmail.com

\section{RESUMO}

Em algumas instituições de educação infantil o que está em conflito é, por um lado, a visão assistencialista e, por outro, a visão voltada para a capacidade de aprendizagem de cunho escolar. Dentro desta complexidade a Educação Física, aqui entendida como cultural do movimento é deixada de lado. Sendo assim, a presente pesquisa teve como objetivo conhecer a produção científica veiculada por um evento nacional acerca da Educação Física nos anos iniciais da educação infantil. Para tanto utilizamos como metodologia de pesquisa aquela denominada de estado da arte ou estado do conhecimento. Optamos como base a ser pesquisada a Associação Nacional de Pós-Graduação e Pesquisa em Educação ANPED. Contudo, notamos que há escassez de pesquisas sobre tema aqui abordado, pois não possui reflexo na base de dados pesquisado. Concluímos que se fazem necessárias pesquisas sobre o tema para que as propostas pedagógicas avancem as de cunho assistencialista e escolarizantes.

Palavras-chave: Educação Infantil; Cuidar e educar; Educação Física; Cultura corporal de movimento; Desenvolvimento infantil.

\section{PHYSICAL EDUCATION IN EARLY CHILDHOOD EDUCATION (0 TO 3 YEARS): THE STATE OF THE ART FROM ANPED PUBLICATIONS}

\begin{abstract}
In some institutions which are in conflict, on the one hand is the welfare view, $\mathrm{n}$ the other, a view toward learning ability of school. Within this complexity Physical Education, here understood as a cultural movement is set aside. Thus, this research used one called state of the art or state of knowledge. To this end, we chose as a database to be searched the National Association of Graduate Studies and Research in Education ANPED. A bibliographical character, this kind of research is challenged to develop a mapping of research, discuss a given topic and how this is being addressed in the academic area. However, we note that there is dearth of research on topic discussed here therefore has no reflection on the database searched. In conclusion we do necessary research on the topic for pedagogical proposals that advance the welfare of nature and school subjects.
\end{abstract}

Keywords : Early Childhood Education; Care and education; Physical Education; Body movement culture; Child Development. 


\section{INTRODUÇÃO}

Existe uma concepção sobre o trabalho com os anos iniciais da Educação Infantil, de que não há muito que se fazer nesta faixa etária por ser bebê ${ }^{1}$. Por um lado, os professores responsáveis ocupam-se com os cuidados básicos: saúde, alimentação e segurança. Entende-se que, neste tipo de atendimento, não há a necessidade da presença de um professor, pois estas são as funções de uma babá. Já em outras situações, há uma tendência onde o intuito é colocar a criança, desde muito cedo, em contato com experiências e saberes de cunho escolar. Não estamos desconsiderando o enriquecimento científico, no entanto, é preciso enfatizar nesta pesquisa a cultura corporal, deixada de lado ou vista como um lazer, onde as crianças são deixadas a mercê do tempo como se não houvesse nada a oferecer a elas. Nossa preocupação não caminha em paralelo com nenhuma destas tendências.

Por esta razão, esta pesquisa foi desenvolvida com o intento de conhecer o que as pesquisas publicadas na ANPED (Associação Nacional de Pós-Graduação e Pesquisas em Educação) apontam sobre a Educação Física na Educação Infantil de zero a três anos. Posteriormente, procuraremos apresentar mesmo que brevemente, algumas indicações teóricas sobre como o professor pode trabalhar com esses elementos da cultura do movimento.

\section{METODOLOGIA}

Para realizar esta pesquisa utilizamos como metodologia aquela denominada de estado da arte ou estado do conhecimento. Apresentando um caráter bibliográfico, esse tipo de pesquisa tem como desafio elaborar um mapeamento das pesquisas e discutir determinada produção acadêmica, além de descrever como o tema vem sendo tratado na área acadêmica e científica. Neste tipo de pesquisa são usadas como fontes básicas de referência para realizar o levantamento dos dados os catálogos de faculdades, institutos, universidades, associações nacionais e órgãos de fomento da pesquisa ${ }^{2}$.

Optamos como base de dados a ser analisada a Associação Nacional de PósGraduação e Pesquisa em Educação (ANPED), mais especificamente o grupo de trabalho 7 (GT7), que trata, especificamente da educação de crianças com faixa etária entre zero a três anos.

Em relação ao espaço tempo escolhido para a busca pelas pesquisas, decidimos, inicialmente, pelos últimos dez anos, o que compreenderia a $28^{a}$ reunião de 2004 até 36ạ reunião de 2013. Tendo em vista a ausência de estudos sobre a temática aqui abordada, estendemos a busca para todas as reuniões disponibilizadas no site do 
evento. Assim, nossa pesquisa compreendeu todas as reuniões anuais da ANPED - 1999 a 2013.

\section{RESULTADOS}

Foram visitadas todas as páginas virtuais das reuniões anuais do evento. Todos os trabalhos e pôsteres divulgados foram pesquisados com o intuito de elencarmos aquelas pesquisas que iriam de encontro ao interesse desta pesquisa. No entanto, nenhuma publicação foi encontrada. Com o intuito de tentarmos contribuir com futuras pesquisas e com a prática do professor, seguiremos com algumas reflexões teóricas no que diz respeito à Educação Física nos anos iniciais da Educação Infantil.

\section{DISCUSSÃO}

A Lei de Diretrizes e Bases da Educação Nacional ${ }^{3}$, estabelece que a Educação Física é componente curricular de toda a Educação Básica. No entanto, percebe-se que professoras de creche não sabem ou não possuem formação que Ihes deem subsídios teóricos e práticos para propor ou conduzir atividades referentes à Educação Física ${ }^{4}$. Além disso, a professora responsável pelo atendimento, não conta com a presença de professores especialistas, tais como, professor de Educação Física. Por isso, enquanto polivalente, precisa desenvolver atividades que envolvam essas áreas da educação.

Aplicada á Educação Infantil, a Educação Física visa integrar as crianças ao mundo, demonstrando a cultura corporal ampliando suas experiências culturais. Por isso não entendemos o desenvolvimento infantil que se dê apenas com cuidados de higiene. Para que a criança se desenvolva fazse necessário a presença de um adulto the ensinando, no caso desta pesquisa, um professor de Educação Física que lance mão dos conteúdos de sua área de atuação para que as crianças se humanizem ${ }^{5}$.

De acordo com a teoria históricocultural, as crianças assimilam a cultura, as qualidades psíquicas, as aptidões e os conhecimentos humanos por meio de heranças sociais. Nenhuma criança pode integrar-se culturalmente de forma espontânea ${ }^{6}$.

Para isso faz-se necessário que o educador tenha uma base sólida de conhecimentos sobre o desenvolvimento infantil. Tendo claro como a criança se desenvolve o professor enquanto mediador cultural conduzirá e orientará a criança em vias de se desenvolver cada vez mais. A teoria histórico-social lança em um de seus conceitos, um novo patamar de ação pedagógica ao professor: ao observar e reconhecer na criança aquilo que ela já internalizou, ou seja, sua zona de 
desenvolvimento real/imediato o professor a lança em seu desenvolvimento potencial. Para esta teoria o ensino deve contribuir para o desenvolvimento ${ }^{4}$.

Ao entender esta situação, o professor usar a zona de desenvolvimento proximal com informações adquiridas anteriormente e avançar, o ensino será uma ótima contribuição para o desenvolvimento da criança ${ }^{5}$.

Sob este entendimento, a intervenção pedagógica do professor torna-se imprescindível, por proporcionar às crianças níveis mais amplos em seu desenvolvimento. O papel do professor é reconhecer o nível de desenvolvimento da criança e contribuir por meio de atividades principais para que avance cada vez mais. Por atividade principal entende-se como aquela que organiza ou dá forma aos processos psíquicos ${ }^{4}$.

As atividades principais são: a comunicação visual direta com o adulto (professor), o olhar, o choro, o balbucio; a segunda atividade é a manipulação de objeto, entre elas o pegar, jogar, por na boca e, a terceira, engloba a brincadeira, imitação (perpetuação/manutenção) das funções sociais (carrinho, casinha) ${ }^{6}$.

Após o nascimento do bebê toda a atenção the é direcionada, pois é completamente dependente de um adulto, por exemplo, utilizar os objetos da cultura, andar, falar, sentir e o auto-controle. Não apenas estas noções práticas, como também, atos psíquicos são resultantes da convivência com os adultos. Sob esta perspectiva, a atuação sobre 0 adulto torna-se imprescindível ${ }^{4}$.

Nos primeiros anos de vida, a criança passa por algumas adaptações. Quando nasce, o bebê tende a se comunicar com o adulto visualmente mesmo que ainda não conheça palavras, não entende gestos do adulto em si. O bebê, em muitos momentos, alegra-se com sua presença e o observa por longos períodos. Esse processo denomina-se comunicação, sendo a primeira adaptação das três atividades principais ${ }^{6}$.

Em seu primeiro e segundo ano de vida, tende a transferir seu interesse para os objetos e, assim que aprende a manipulá-los, o bebê se torna mais autônomo, nesta etapa faz de tudo para chamar a atenção ouvir elogios do adulto ${ }^{6}$. É neste sentido que Elkonin ${ }^{7}$ caracteriza como atividade principal deste período a atividade objetal manipulatória.

O passo seguinte é a imitação, a partir dos três anos de idade ou até antes, a criança passa imitar o adulto em questão, por mais que seja um faz de conta a interpretação já é considerável. Com esta nova capacidade, a criança cria um mundo imaginário a partir de suas vivências anteriores. A criança faz de conta e brinca de tudo o que for capaz de brincar, sua terceira atividade principal ${ }^{4}$. 
As principais influências teóricas da Educação Física na pré-escola é a recreação, a psicomotricidade e o desenvolvimento motor $^{8}$. Em contrapartida, o Coletivo de Autores $^{9}$, mesmo não abordando diretamente nosso tema rompem com as abordagens tradicionais onde o professor avalia a criança apenas em seu aspecto motor. Ante essas constatações, nos perguntamos: existe a possibilidade de um diálogo entre a Educação Física e Educação Infantil?

A criança pode aprender com 0 professor ou até mesmo em cooperação com outras crianças, e, assim o conhecimento vai adquirindo forma e o processo ensinoaprendizagem é inserido aos poucos sempre do simples para o complexo e o que hoje a criança faz com ajuda ou em cooperação, amanhã fará sozinha. É com esta preocupação é que enxergamos a possibilidade de inserir na educação infantil os conteúdos da Educação Física.

De acordo com o Referencial Curricular Nacional para a Educação Infantil (RCNEI), o lúdico é um ponto importante na educação infantil para a construção do conhecimento, pois, é por meio dele que as crianças transformam os conhecimentos anteriormente adquiridos com a imaginação e a imitação de alguém, é onde o aprendizado flui ${ }^{10}$.
Por meio dessas atividades, em ambientes favoráveis, o educador irá explorar mais a criatividade melhorando sua conduta e auto-estima, por isso que atividades lúdicas devem fazer parte de seu planejamento na proposta de trabalho. Como o desenvolvimento e a aprendizagem caminham juntos, desde que o nascimento da criança, é importante a vivência de atividades de caráter lúdicas, pois oferecem mais do que uma simples apropriação do saber.

Podemos dizer que essa inserção pode significar um grande avanço para a Educação Física. Sendo assim, temos muito que refletir sobre o espaço da Educação Física na Educação Infantil. Uma das dificuldades encontradas pelos professores é a rotatividade, em outras palavras, o rodízio dos professores para aplicar aulas de Educação Física nas creches. Com isso, a construção de um trabalho de qualidade impede de ser concretizado, de modo que, muitas vezes, os professores contratados chegam ao local de trabalho sem a formação adequada para atuar com as crianças pequenas, realizando as atividades no improviso. No entanto, após certo tempo quando o professor contratado esta se adequando a proposta da Pedagogia da Educação Infantil, precisa sair da unidade, por ser temporário, prejudicando o 
aprendizado das crianças sobre cultura corporal $^{8}$.

\section{CONCLUSÕES}

Para o professor realizar uma aula, faz-se necessário estudo contínuo e o conhecimento de conteúdos basilares, com a finalidade de aprimorar-se. Para que se tenha um embasamento teórico precisa-se de conteúdos a serem analisados e entendidos. Contudo, notamos certa problemática ao desenvolvermos nossa pesquisa em relação as publicações da ANPED no que tange a Educação Física nos primeiros anos da Educação Infantil.

Sobre esta problemática, queremos destacar nossa primeira consideração: é preciso que haja mais pesquisas direcionadas à Educação Física nos anos iniciais da Educação Infantil. Trata-se de um tema que necessita de atenção e um devido comprometimento pois, de acordo com a pesquisa realizada, há poucos estudos que se preocupam com a temática. Novas pesquisas podem contribuir para que tendências assistencialistas e escolarizantes na Educação Infantil sejam superadas.

\section{REFERÊNCIAS}

1 - MARTINS, L. M. O ensino e o desenvolvimento da criança de zero a três anos. In: ARCE, A.; MARTINS, L. M. Ensinando aos pequenos: de zero a três anos. Campinas: Alínea, 2009, 93-121.
2 - FERREIRA, N. S. de A. As pesquisas denominadas "estado da arte". Educação \& Sociedade, Campinas, ano XXIII, n. 79, p.

257-272, ago. 2002. http://dx.doi.org/10.1590/S010173302002000300013

3 - BRASIL. Lei de Diretrizes e Bases da Educação Nacional. Lei n. 9.394/96, de 20 de dezembro de 1996.

4 - SILVA, J. R. A Brincadeira na Educação Infantil: uma experiência de pesquisa e intervenção. 2012. 171 f. Dissertação (Mestrado em Educação) - Faculdade de Ciências e Tecnologia, Universidade Estadual Paulista, Presidente Prudente, 2012.

5 - VIGOTSKI, L. S. A formação social da mente. São Paulo: Martins Fontes, 2008.

6 - MUKHINA, V. Psicologia da Idade Préescolar. Martins Fontes, São Paulo, 1996.

7 - ELKONIN, D. B. Psicologia do jogo. São Paulo: Martins Fontes, 1998

8 - SAYAO, D. T. Educação Física na educação infantil: riscos, conflitos e controvérsias. Motrivivência, Ano XI, n2 13, Novembro/1999, 221-238.

9 - COLETIVO DE AUTORES. Metodologia do ensino de educação física. São Paulo: Cortez, 2009.

10 - BRASIL. Ministério da educação e do Desporto. Secretaria de Educação Fundamental (1998). Referencial Curricular Nacional Para a Educação Infantil. Brasília: $\mathrm{MEC} / \mathrm{SEF} / \mathrm{DPE} / \mathrm{COEDI}$.

Recebido para publicação em 01/08/2014 Revisado em 19/09/2014 Aceito em 22/09/2014 